\title{
约 \\ PRAGMATISMO OU IDEOLOGIA? \\ SETORES EMPRESARIAIS E FINANCIAMENTO DE CAMPANHA EM 2014
}

\author{
PRAGMATISM OR IDEOLOGY? \\ BUSINESS SECTORS AND CAMPAIGN FINANCING IN 2014
}

\section{PRAGMATISMO O IDEOLOGÍA? SECTORES EMPRESARIALES Y FINANCIAMIENTO ELECTORAL EN 2014}

\author{
Wagner Pralon Mancuso ${ }^{1}$ \\ Rodrigo Rossi Horochovski ${ }^{2}$ \\ Ivan Jairo Junckes ${ }^{3}$ \\ Neilor Fermino Camargo ${ }^{4}$
}

\begin{abstract}
Resumo: Este trabalho apresenta um estudo do comportamento doador de setores empresariais nas eleições brasileiras de 2014, focalizando a disputa por dois cargos: presidente da república e deputado federal. Aplicando as técnicas de análise de redes sociais e de regressão linear múltipla aos dados sobre financiamento eleitoral divulgados pelo Tribunal Superior Eleitoral (TSE), o artigo mostra que importantes setores econômicos, as principais candidaturas presidenciais e os maiores partidos políticos formaram em 2014 uma elite político-econômica altamente interconectada, cujas relações internas são marcadas por critérios pragmáticos, em vez de ideológicos.
\end{abstract}

Palavras-chave: Financiamento de campanha eleitoral; Setores empresariais; Eleições brasileiras de 2014.

Abstract: This article studies the behavior of business sectors as campaign donors in the 2014 Brazilian elections for president and federal deputy. By applying social network analysis and multiple linear regression to the data on electoral financing divulged by the Brazilian Superior Electoral Court, this article shows that important business sectors, the main presidential candidacies, and the largest political parties formed a highly interconnected political-economic elite, whose internal relationships are based in pragmatic rather than ideological criteria.

Keywords: Electoral campaign finance; Business sectors; 2014 Brazilian elections.

\footnotetext{
${ }^{1}$ Professor do curso de graduação em gestão de políticas públicas da Escola de Artes, Ciências e Humanidades da Universidade de São Paulo (EACH-USP). Professor dos programas de pós-graduação em ciência política e relações internacionais da USP. E-mail: pralon@ usp.br Orcid: 0000-0002-2071-2270

2 Professor do curso de administração pública e do programa de pós-graduação em desenvolvimento territorial sustentável da Universidade Federal do Paraná (UFPR), Setor Litoral. Professor do programa de pós-graduação em ciência política da UFPR. E-mail: rodrigoh33@gmail.com Orcid: 0000-0003-1135-0543

${ }^{3}$ Professor do curso de administração pública e do programa de pós-graduação em desenvolvimento territorial sustentável da Universidade Federal do Paraná (UFPR), Setor Litoral. E-mail: ivanjairojunckes@gmail.com Orcid: 0000-0001-8305-3754

${ }^{4}$ Professor do curso de administração pública da Universidade Federal do Paraná (UFPR), Setor Litoral. Doutorando no programa de pós-graduação em ciência política da UFPR. E-mail: camargon@ gmail.com Orcid: 0000-0003-24693537
} 
Resumen: Este documento presenta un estudio del comportamiento de los sectores empresariales donantes en las elecciones brasileñas de 2014, centrándose en la disputa por dos cargos: presidente de la república y diputado federal. Aplicando las técnicas de análisis de redes sociales y regresión lineal múltiple a los datos sobre financiamiento electoral publicados por el Tribunal Superior Electoral brasileño, el artículo muestra que importantes sectores económicos, las principales candidaturas presidenciales y los principales partidos políticos en 2014 formaron una élite política e económica altamente interconectada, cuyas relaciones internas están marcadas por criterios pragmáticos más que ideológicos.

Palabras clave: Financiamiento electoral; Sectores empresariales; Elecciones brasileñas de 2014

\section{Introdução}

Uma decisão do Supremo Tribunal Federal (STF), tomada em setembro de 2015, baniu o financiamento eleitoral por empresas no Brasil. No entanto, o setor privado se destacou como a principal fonte de recursos para as campanhas políticas do país durante um período de 21 anos, que se estendeu desde 1994 - primeira eleição do recente período democrático em que o financiamento empresarial foi admitido pelo ordenamento jurídico pátrio - até a publicação do acórdão da Suprema Corte. Ao longo deste período, o dinheiro das firmas financiou fartamente seis eleições nacionais e cinco eleições municipais.

A ciência política começou a debruçar-se sobre os dados referentes às contribuições eleitorais de empresas brasileiras a partir dos trabalhos de Samuels (2001a; 2001b; 2001c; 2001d; 2002), que focalizou as eleições de 1994 e 1998. Entretanto, o boom da literatura sobre o tema ocorreu a partir do momento em que a justiça eleitoral passou a compilar e disponibilizar, em meio eletrônico, na rede mundial de computadores, as informações relativas às doações de campanha. Hoje, o Repositório de Dados Eleitorais do Tribunal Superior Eleitoral (TSE) disponibiliza as informações oficiais sobre financiamento de campanhas para todos os pleitos realizados no país desde $2002^{5}$.

Uma parte da literatura constituída desde então se dedicou ao estudo das doações empresariais como um todo, ora explorando seus fatores determinantes, ora abordando seus efeitos sobre o desempenho dos candidatos, mas sempre tomando o conjunto geral das contribuições empresariais, sem descer às contribuições feitas por CNPJs específicos (SANTOS, 2009; CERVI, 2010; ARAÚJO, SILOTTO e CUNHA, 2015; HOROCHOVSKI et al., 2015; MANCUSO e SPECK, 2015a; MANCUSO e SPECK, 2015b; MANCUSO et al. 2016; SPECK, 2016). Pode-se dizer, pois, que este primeiro segmento da produção acadêmica nacional lançou um olhar sobre a macrodinâmica do fenômeno de interesse.

Já outra parte da literatura pesquisou o quid pro quo envolvido no financiamento eleitoral feito por empresas específicas, buscando entender se as doações dessas empresas resultaram ou não em benefícios particulares para elas, em termos, por exemplo, de (i) desempenho econômico

$5 \mathrm{O}$ endereço é: <http://www.tse.jus.br/eleicoes/estatisticas/repositorio-de-dados-eleitorais-1/repositorio-de-dadoseleitorais> 
geral (BANDEIRA de MELLO e MARCON, 2005), (ii) acesso ao crédito de bancos públicos (CLAESSENS, FEIJEN e LAEVEN, 2008; LAZZARINI et al., 2011; ROCHA, 2011; LOPES, 2016), e (iii) acesso a contratos com o governo (ARAÚJO, 2012; BOAS, HIDALGO e RICHARDSON, 2014). Este segundo segmento da literatura lançou, portanto, um olhar sobre a microdinâmica das contribuições eleitorais empresariais.

Entre esses dois polos predominantes e complementares da literatura constituiu-se ainda um terceiro segmento, ao qual o presente trabalho se filia, e que lançou seu olhar para as doações de campanha feitas por diferentes setores econômicos do empresariado, formando-se assim um enfoque de alcance meso. Neste segmento inclui-se, por exemplo, o trabalho de Mancuso, Horochovski e Camargo (2016), que esquadrinhou o fluxo de financiamento eleitoral procedente dos diversos setores da economia brasileira e destinado às campanhas presidenciais de 2014. Outras obras pertencentes à mesma vertente da literatura, porém mais interessadas no efeito das contribuições setoriais sobre decisões e comportamentos políticos, são Araújo (2008) e Santos (2016). Araújo (2008) não observou correlação entre doações eleitorais e proteção comercial a ramos específicos do empresariado brasileiro, via desvios da Tarifa Externa Comum (TEC) do Mercosul. Santos (2016), por sua vez, verificou afluxo de financiamento setorial para deputados (i) que pertencem a comissões permanentes da Câmara que tratam de assuntos relevantes para os doadores de campanha, (ii) que relatam medidas provisórias (MPs) de interesse para os financiadores, e (iii) que propõem emendas às MPs em benefício dos contribuidores.

O objetivo geral deste trabalho é analisar o comportamento de diferentes segmentos empresariais como financiadores de campanhas nas eleições de 2014. As questões que o artigo procura discutir são as seguintes: que setores empresariais mais se destacaram como fontes de recursos eleitorais naquela eleição? Como os diversos setores distribuíram seus recursos entre candidatos e partidos políticos? Que subconjunto de setores, candidatos e partidos ocuparam posições mais centrais na rede de financiamento eleitoral na campanha de 2014? Por fim, que fator explica melhor o comportamento doador dos setores: pragmatismo ou ideologia?

Para atingir esse objetivo e responder essas questões, o trabalho está dividido em três partes, além desta introdução. A primeira explica a sistemática do financiamento eleitoral na campanha de 2014. A segunda contém a metodologia de pesquisa aplicada neste estudo. A terceira apresenta e discute os resultados. As considerações finais retomam as principais conclusões do artigo e apontam possíveis desdobramentos da investigação iniciada aqui.

\section{O financiamento eleitoral nas eleições de 2014}

No tocante ao financiamento político, o Brasil historicamente adotou um modelo misto, combinando fontes privadas e públicas de recursos. Seu desenho ficou praticamente inalterado por duas décadas, entre 1994 e 2014, e presidiu as eleições desse último ano. É, portanto, de tal desenho que tratamos aqui. 
Em 2014, as principais fontes privadas foram as pessoas jurídicas, as pessoas físicas, e os próprios candidatos, em conformidade com as Leis $\mathrm{n}^{\circ}$ 9.096/1995 e 9.504/1997 - respectivamente Lei dos Partidos Políticos e Lei das Eleições (BRASIL, 1995, 1997). No que se refere às pessoas jurídicas, as empresas podiam doar até dois por cento de seu faturamento bruto declarado à Receita Federal no ano-exercício anterior ao da eleição. As pessoas físicas, por seu turno, podiam doar até dez por cento de seus rendimentos brutos, declarados para o Imposto de Renda, também no ano-exercício anterior ao da eleição. Outra fonte importante de origem privada eram os recursos dos próprios candidatos, que podiam fazer doações até o limite de despesas definido por seus partidos para as campanhas aos cargos a que concorriam.

A fonte pública de financiamento eleitoral foi o Fundo Especial de Assistência Financeira aos Partidos Políticos, conhecido como Fundo Partidário (FP). Distribuído anualmente e disciplinado pela Lei n ${ }^{\circ}$ 9.096/1997, o FP era composto (e ainda é) de dotações orçamentárias da União, multas e penalidades pecuniárias, no montante mínimo de 35 centavos de real por eleitor, em valores de agosto de 1995, corrigidos pelo IGP-DI/FGV e multiplicados pelo eleitorado total em cada ano. Na prática, o FP costumeiramente ultrapassou esse piso. A partilha do FP obedeceu ao seguinte critério: cinco por cento divididos igualmente entre os partidos com registro definitivo e 95 por cento divididos proporcionalmente ao desempenho de cada partido nas últimas eleições para deputado federal. O FP não se destinava exclusivamente ao financiamento de campanhas, dado que era dele que os partidos obtinham recursos para sua manutenção, porém uma parte do FP foi aplicada nas eleições.

Além dessas fontes principais, outras fontes eram os rendimentos de aplicações financeiras dos recursos arrecadados, a comercialização de bens e serviços e as doações pela internet. No entanto, a somatória dessas modalidades sempre foi muito inferior a um por cento dos recursos transacionados nas campanhas, razão porque não as detalhamos.

Nas duas décadas em que este modelo prevaleceu, o dinheiro de origem privada, mormente empresarial, preponderou de maneira quase absoluta - em 2014, as empresas sozinhas foram responsáveis por mais de 72 por cento de todas as receitas declaradas por candidatos, partidos e comitês financeiros. No entanto, o pleito em apreço foi o último com tal dinâmica, já que, em 2015, as doações empresariais foram proibidas pelo Supremo Tribunal Federal (STF), como resultado do julgamento da Ação Direta de Inconstitucionalidade (ADI) n ${ }^{\circ} 4.650$, interposta pela Ordem dos Advogados do Brasil (OAB) ${ }^{6}$.

Uma característica importante do modelo que regeu as eleições de 2014 foi a flexibilidade não apenas nos limites de doação, mas também nos caminhos percorridos pelos recursos. À

6 Para suprir, ainda que parcialmente, a ausência do financiamento empresarial, a Lei $\mathrm{n}^{\circ}$ 13.487/2017 estabeleceu o Fundo Especial de Financiamento de Campanha (FEFC), conhecido como fundo eleitoral. Distribuído também conforme o desempenho dos partidos em eleição geral anterior, para as eleições de 2018 somou 1,7 bilhão de reais, pouco mais da metade do que as empresas doaram em 2014. 
exceção de pessoas físicas e empresas, que podiam apenas doar, os demais atores que participaram do processo - ou seja, candidatos, partidos e comitês financeiros - podiam receber, doar e/ou repassar recursos recebidos. Ocorre que, até aquele pleito, não havia como identificar esses fluxos quando o dinheiro recebido como doação empresarial pelo partido era repassado para algum candidato. Nesse sentido, a principal novidade naquele ano foi o Tribunal Superior Eleitoral (TSE), por meio da Resolução ${ }^{\circ}$ 23.406/2014, impor a obrigatoriedade de os prestadores de contas identificarem a fonte original dos recursos quando se tratasse de repasses. Assim, por exemplo, se uma empresa efetuasse uma doação a um diretório partidário e este a redirecionasse para um candidato, a prestação de contas do candidato teria de informar que aquela empresa era a fonte originária do recurso que veio do partido. O objetivo desta resolução foi combater doações ocultadas, isto é, doações de uma empresa para um agente dissimuladas pela mediação de outro agente. Tal medida possibilitou pesquisas como a que apresentamos neste artigo, em que as candidaturas têm todas as doações empresariais identificadas, sejam elas diretas, sejam indiretas.

\section{Metodologia}

Este artigo focaliza as doações eleitorais oficiais realizadas pelos diferentes setores econômicos nas eleições de 2014. Isso significa dizer que o trabalho trata exclusivamente das contribuições formalmente declaradas por empresas à Justiça Eleitoral. Uma quantidade de recursos muito difícil de mensurar pode ter fluido de empresas para candidatos, comitês e partidos por vias não oficiais, sob a forma de "caixa 2". O trabalho não tem como abranger tais recursos, por causa da natureza velada dos repasses ilícitos. De toda forma, as doações empresariais oficiais atingiram cifras bilionárias, indicando a importância de se debruçar sobre os repasses lícitos, ainda que eles admitidamente não contenham toda a história do financiamento eleitoral empresarial no pleito sob análise.

$\mathrm{O}$ artigo trata especificamente das contribuições empresariais destinadas a candidatos e partidos que disputaram dois cargos de nível nacional: o de presidente da república e o de deputado federal. O primeiro passo da pesquisa foi baixar do Repositório de Dados Eleitorais do TSE a prestação de contas de todas as candidaturas a esses cargos que foram deferidas pela justiça eleitoral. No caso da disputa pela chefia do executivo nacional, incluímos também as prestações de contas dos comitês financeiros nacionais para presidente da república, tomando o cuidado de excluir repasses entre as contas das candidaturas e dos comitês, e vice-versa, para evitar a dupla contagem dos mesmos recursos.

Em segundo lugar, filtramos nas prestações de contas todas as doações empresariais, tanto as diretas - registradas como recursos de pessoas jurídicas -, quanto as indiretas - registradas como recursos de partido político ou de outros candidatos e comitês, porém com os doadores originários devidamente identificados, conforme explicado na seção anterior. Durante a campanha de 2014, o empresariado destinou $\mathrm{R} \$ 605.815 .280,25$ à eleição presidencial e 
R \$780.038.292,83 à eleição para a Câmara dos Deputados.

Em terceiro lugar, agregamos as doações empresariais diretas e indiretas segundo a seção do doador na Classificação Nacional das Atividades Econômicas (CNAE). No caso da eleição à presidência, a agregação foi feita para cada uma das 11 candidaturas. Já no caso da eleição para deputado federal, a agregação foi feita para cada um dos 32 partidos que lançaram candidatos a esse cargo.

Em quarto lugar, submetemos os dados obtidos a duas técnicas de análise. Primeiro, à análise de redes sociais, com o duplo intuito de confeccionarmos grafos das relações entre setores econômicos, candidatos e partidos, bem como de calcularmos uma série de métricas referentes a essas relações. Segundo, à regressão linear múltipla, para testarmos hipóteses sobre fatores potencialmente explicativos do comportamento doador dos principais segmentos econômicos envolvidos na campanha para deputado federal de 2014.

\section{Resultados:}

Análise de redes

A maioria das pesquisas sobre financiamento político no Brasil baseia-se em atributos estáticos dos atores que participam do processo. Desse modo, variáveis como gênero, renda, escolaridade, partido, capital político, porte e ideologia do partido, além de tipo e capacidade econômica do financiador, entre outras, são mobilizadas a partir de diferentes abordagens, porém com uma predominância de modelos estatísticos descritivos e inferenciais. Tal estratégia gerou um acúmulo de estudos de qualidade, que logrou descrever o fenômeno com acurácia, constituindo, como vimos anteriormente, um campo próprio dentro da ciência política brasileira (MANCUSO, 2015).

A metodologia de análise de redes sociais (ARS) contribui com as pesquisas baseadas em atributos estáticos dos atores ao introduzir uma perspectiva relacional. Isso ocorre porque as estatísticas de rede são geradas a partir não das características específicas dos atores, mas sim dos vínculos ou fluxos que eles estabelecem com outros atores em uma teia de relações sociais, o que permite identificar quem é central e quem é periférico, ou seja, quem concentra e quem está alijado de recursos de poder. No caso do nosso tema, financiamento eleitoral, os atores - doadores e receptores de recursos - são os nós e as doações compõem as arestas, ou seja, os fluxos que conectam os atores produzindo os vínculos constituintes de uma rede social.

Uma série de trabalhos que analisam redes de financiamento político tem sido publicada nos últimos anos (CERVI; HOROCHOVSKI et al., 2015; HOROCHOVSKI et al., 2016; JUNCKES et al., 2014; SILVA et al., 2017; JUNCKES et al., 2019). Este artigo segue esta linha investigativa, com foco em como os setores empresariais financiam a política. Conforme dito na seção anterior, para operacionalizar esta parte da pesquisa, todas as empresas que doaram para as campanhas nas eleições de 2014 - diretamente aos candidatos ou indiretamente via partidos e 
comitês - foram agrupadas conforme sua classificação nas seções da Classificação Nacional de Atividades Econômicas (CNAE). Os dados empíricos e sua discussão referem-se a dois cargos de nível federal - Presidente da República e Deputado Federal. Ao longo da exposição, explicamos as estatísticas de rede conforme elas se apresentem ${ }^{7}$.

Para compor o que doravante chamamos de rede presidente, somamos todas as doações das empresas classificadas dentro de cada seção CNAE para cada um dos oito candidatos que disputaram a Presidência da República em 2014 e receberam doações empresariais ${ }^{8}$. A Figura 1 é o grafo desta rede e permite visualizar o fluxo de dinheiro entre setores empresariais e candidaturas. Os nós, ou círculos, estão dimensionados pelo grau ponderado, ou seja, o valor total que doaram ou receberam. A espessura das arestas indica os fluxos de recursos entre os nós, i. e., a quantia transacionada entre os pares de nós que elas conectam. As cores dos nós representam os tipos: verdes são candidatos, vermelhos, setores empresariais. Aplicamos uma distribuição/leiaute, Fruchterman-Reingold, cujo algoritmo busca destacar os nós mais centrais e aproximar os que se relacionam mais intensamente.

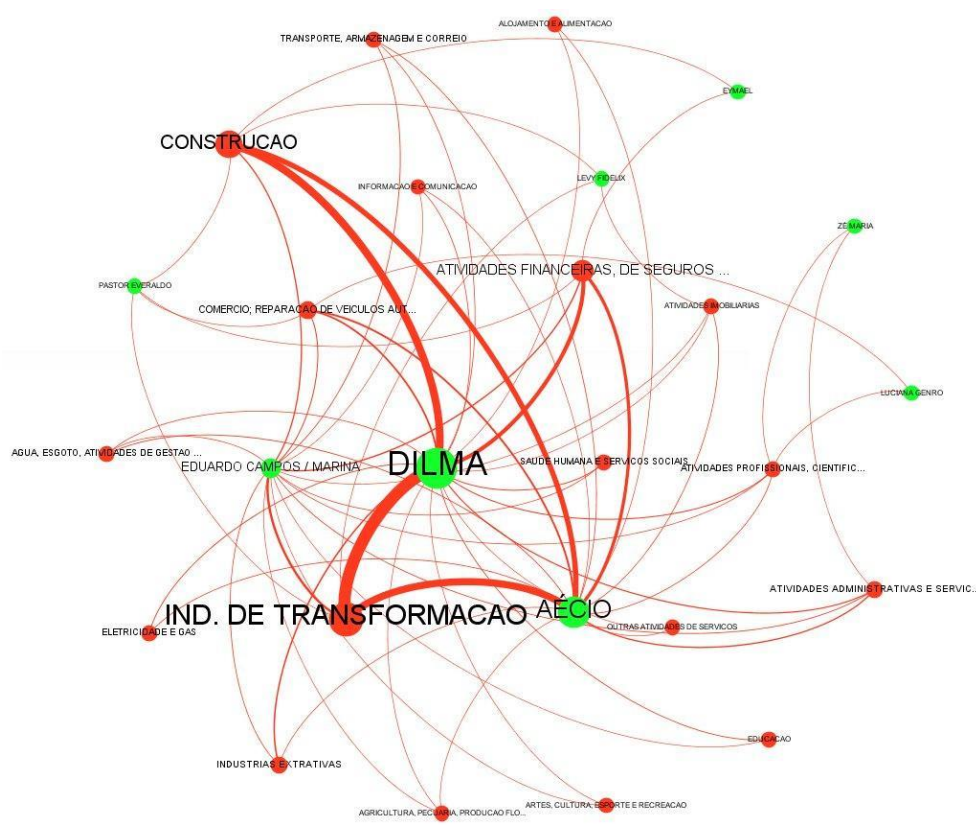

Figura 1 - Grafo Rede Presidente

Fonte: elaboração própria com dados do TSE

A primeira métrica de rede que exploramos é a centralidade de grau, a medida mais simples da ARS, já que consiste no número de arestas que partem de ou chegam a um determinado nó. Em grafos dirigidos, nos quais a direção da aresta importa para as análises, o grau pode ser de entrada ou saída, correspondendo na nossa rede, respectivamente, às doações que entraram para

7 Vasta literatura explica detalhadamente os cálculos das medidas que empregamos neste paper. Entre as obras consultadas, destacamos Degenne e Forsé, 1999; Scott, 2012; Higgins e Ribeiro, 2018; Lemieux, Ouimet e Pereira, 2008; Newman, 2018.

8 De acordo com os dados do TSE, três candidaturas não receberam doações empresariais diretas ou indiretas: Eduardo Jorge (PV), Mauro Iasi (PCO) e Rui Pimenta (PSTU). 
o candidato ou saíram da seção CNAE.

As Tabelas 1 e 2 mostram, em primeiro lugar, que as três candidaturas que chegaram à frente na disputa - Dilma, Aécio e Eduardo/Marina - são justamente as que apresentam o maior grau de entrada. A CNAE tem, ao todo, 21 seções (identificadas por letras que vão de A a U), que correspondem ao conjunto de setores que formam a economia brasileira. A candidata do PT recebeu doações de 18 setores, ou seja, de todos os setores econômicos que doaram algum valor para a campanha dos candidatos à Presidência, enquanto os outros dois postulantes receberam doações de 15 setores. Os demais candidatos receberam de quatro setores, ou menos. Embora esta medida seja muito simples, não exprimindo os valores transacionados, nem o peso de cada setor nas candidaturas, ela mostra que as principais candidaturas serviram como polo de atração das contribuições feitas pela maior parte dos setores doadores. Daí a importância, destacada pela literatura, de sempre se considerar uma possível endogenia no estudo do financiamento eleitoral: se é verdade que as doações podem favorecer o desempenho nas urnas dos candidatos contemplados, também é verdade que a expectativa de desempenho dos candidatos (mensurada, por exemplo, pelas pesquisas eleitorais) pode afetar o fluxo de doações a eles dirigidas.

O grau de saída assinala quais são os setores que doam para mais candidatos, estrategicamente distribuindo seus ovos no maior número de cestas. Chama a atenção que nenhum dos 18 setores doadores doou para apenas um candidato. Os setores que repartiram suas contribuições entre o maior número de candidaturas foram Construção (que doou para seis candidatos) e, em seguida, quatro setores que doaram para cinco concorrentes: Indústria de transformação; Comércio, reparação de veículos automotores e motocicletas; Atividades financeiras, de seguros e serviços relacionados; e Atividades profissionais, científicas e técnicas.

Tabela 1 - Métricas de centralidade - Atores políticos da Rede presidente

\begin{tabular}{|c|c|c|c|c|c|c|}
\hline Ator & $\begin{array}{c}\text { Grau } \\
\text { entrada* }\end{array}$ & Grau saída ${ }^{*}$ & Grau pond. entrada & $\begin{array}{c}\text { Grau pond. } \\
\text { saída }\end{array}$ & $\begin{array}{c}\text { Proximi } \\
\text { dade }^{* *}\end{array}$ & $\begin{array}{c}\text { Interme } \\
\text { diação }\end{array}$ \\
\hline Dilma & 18 & 0 & $333.707 .824,50$ & 0,00 & 0,86 & 0,35 \\
\hline Aécio & 15 & 0 & $213.941 .381,58$ & 0,00 & 0,78 & 0,22 \\
\hline $\begin{array}{l}\text { Eduardo Campos / } \\
\text { Marina }\end{array}$ & 15 & 0 & $56.399 .084,76$ & 0,00 & 0,78 & 0,22 \\
\hline Pastor Everaldo & 4 & 0 & $1.038 .385,40$ & 0,00 & 0,48 & 0,01 \\
\hline Levy Fidelix & 3 & 0 & $295.000,00$ & 0,00 & 0,44 & 0,003 \\
\hline Eymael & 2 & 0 & $371.995,35$ & 0,00 & 0,41 & 0,001 \\
\hline Luciana Genro & 2 & 0 & $56.000,00$ & 0,00 & 0,41 & 0,002 \\
\hline Zé Maria & 2 & 0 & $5.608,66$ & 0,00 & 0,40 & 0,001 \\
\hline
\end{tabular}

* Como nesta rede o fluxo é unidirecional (ou seja, um ator só doa ou só recebe), optamos por apresentar apenas as medidas de grau de entrada e de saída que, neste caso, correspondem ao grau de cada nó. ** Centralidade de intermediação harmonizada.

Fonte: elaboração própria com dados do TSE. 
Tabela 2 - Métricas de centralidade - Atores corporativos da Rede presidente

\begin{tabular}{|c|c|c|c|c|c|c|}
\hline Ator & $\begin{array}{c}\text { Grau } \\
\text { entrada }\end{array}$ & $\begin{array}{l}\text { Grau } \\
\text { saída }\end{array}$ & $\begin{array}{c}\text { Grau pond. } \\
\text { entrada }\end{array}$ & Grau pond. saída & $\begin{array}{c}\text { Proximi } \\
\text { dade }^{* *}\end{array}$ & $\begin{array}{c}\text { Interme } \\
\text { diação }\end{array}$ \\
\hline Construção & 0 & 6 & 0,00 & $158.795 .678,14$ & 0,61 & 0,08 \\
\hline Indústrias de Transformação & 0 & 5 & 0,00 & $251.834 .784,97$ & 0,58 & 0,04 \\
\hline $\begin{array}{l}\text { Atividades Financeiras, de Seguros e } \\
\text { Serviços Relacionados }\end{array}$ & 0 & 5 & 0,00 & $87.012 .185,23$ & 0,58 & 0,05 \\
\hline $\begin{array}{l}\text { Comércio; Reparação de Veículos } \\
\text { Automotores e Motocicletas }\end{array}$ & 0 & 5 & 0,00 & $35.682 .064,26$ & 0,58 & 0,06 \\
\hline $\begin{array}{l}\text { Atividades Profissionais, Científicas } \\
\text { e Técnicas }\end{array}$ & 0 & 5 & 0,00 & $7.989 .836,98$ & 0,58 & 0,08 \\
\hline $\begin{array}{l}\text { Atividades Administrativas e } \\
\text { Serviços Complementares }\end{array}$ & 0 & 4 & 0,00 & $18.330 .619,74$ & 0,55 & 0,04 \\
\hline Atividades Imobiliárias & 0 & 4 & 0,00 & $2.215 .000,00$ & 0,55 & 0,02 \\
\hline Indústrias Extrativas & 0 & 3 & 0,00 & $14.515 .000,00$ & 0,53 & 0,002 \\
\hline Transporte, Armazenagem e Correio & 0 & 3 & 0,00 & $5.707 .930,00$ & 0,53 & 0,002 \\
\hline $\begin{array}{l}\text { Água, Esgoto, Atividades de Gestão } \\
\text { de Resíduos e Descontaminação }\end{array}$ & 0 & 3 & 0,00 & $5.705 .009,03$ & 0,53 & 0,002 \\
\hline Informação e Comunicação & 0 & 3 & 0,00 & 2.327.971,90 & 0,53 & 0,002 \\
\hline $\begin{array}{l}\text { Agricultura, Pecuária, Produção } \\
\text { Florestal, Pesca e Aquicultura }\end{array}$ & 0 & 3 & 0,00 & $422.000,00$ & 0,53 & 0,002 \\
\hline Saúde Humana e Serviços Sociais & 0 & 2 & 0,00 & $5.950 .000,00$ & 0,5 & 0,001 \\
\hline Eletricidade e Gás & 0 & 2 & 0,00 & $5.680 .000,00$ & 0,5 & 0,001 \\
\hline Educação & 0 & 2 & 0,00 & $2.753 .000,00$ & 0,5 & 0,001 \\
\hline Alojamento e Alimentação & 0 & 2 & 0,00 & $505.000,00$ & 0,5 & 0,001 \\
\hline Outras Atividades de Serviços & 0 & 2 & 0,00 & $335.000,00$ & 0,5 & 0,001 \\
\hline Artes, Cultura, Esporte e Recreação & 0 & 2 & 0,00 & $54.200,00$ & 0,5 & 0,001 \\
\hline
\end{tabular}

Fonte: elaboração própria com dados do TSE.

O fluxo de dinheiro entre setores empresariais e candidaturas é obtido mediante os graus ponderados de entrada e de saída, pelos quais cada nó apresenta um valor conforme a soma dos pesos das arestas que a ele chegam ou dele saem. Em nossa rede, este peso representa o valor monetário dos recursos transacionados. Aqui a ordem dos principais atores se repete. Os três candidatos mais bem colocados nas eleições são também os mais centrais em grau ponderado de entrada, concentrando $99,8 \%$ do total de 605,8 milhões de reais aportados pelas empresas nas campanhas presidenciais. Frise-se, no entanto, que se trata de uma concentração assimétrica: Dilma recebeu 55,1\% deste total, ao passo que Aécio recebeu 35,3\% e Eduardo Campos/Marina Silva, 9,4\%. Também há concentração na saída, pois $82,1 \%$ dos recursos doados são altamente concentrados por apenas três dos 18 setores econômicos que financiaram campanhas: Indústrias de transformação, responsável por $41,6 \%$ do total das contribuições; Construção, que proporcionou 25,1\% do total; e Atividades financeiras, de seguros e serviços relacionados, fonte de 14,4\% dos recursos. Trabalho anterior de Mancuso, Horochovski e Camargo (2016) mostra que esses percentuais são muito mais altos que a participação dos três setores no valor adicionado 
bruto (VAB) da economia brasileira em 2014: respectivamente, $12 \%, 6,2 \%$ e 6,4\%. Isso sugere que os setores focalizados possuem razões relevantes para financiar a eleição presidencial. Entender melhor as causas do distinto comportamento doador dos diferentes setores econômicos da complexa economia brasileira é um desafio que compõe a agenda de pesquisa de nosso campo. Voltaremos a esse ponto nas considerações finais.

O grafo da Figura 1 ilustra o comportamento das demais estatísticas de rede geradas para este trabalho. A centralidade de proximidade representa a distância média entre determinado nó e os demais nós da rede. Quanto maior o índice, mais perto um ator está dos demais atores, seja ele um candidato ou setor empresarial, no caso da rede investigada. A centralidade de intermediação é a frequência média com que um nó se coloca nos menores caminhos (geodésias) que ligam os demais nós da rede, sendo tratada pela literatura como medida da influência de um ator social. Nesse caso, maior número significa maior frequência nesta medida. Estabelecemos que o software trabalhasse com medidas normalizadas (entre 0 e 1 ) para ambas as centralidades.

$\mathrm{Na}$ rede presidente, os atores praticamente ocupam as mesmas posições em ambas as variáveis, o que seria de se esperar em uma rede pequena (em função das agregações realizadas) e altamente conectada. Desse modo, Dilma, Aécio e Eduardo/Marina lograram colocar-se em posições privilegiadas perante o empresariado. E vice-versa. Os setores empresariais, em sua quase totalidade, se aproximaram desses candidatos, dessa maneira conectando-se entre si. Essa configuração nos permite falar na existência de uma elite político-empresarial que, no caso da competição eleitoral, orienta-se por estratégias pragmáticas que maximizem suas preferências ideologia e preconceitos ficam em segundo plano, seja entre as candidaturas, seja entre os setores empresariais (MCMENAMIN, 2012).

Nas eleições para deputado federal, repetimos os procedimentos para o que doravante denominamos rede deputado federal, cujos nós doadores são os mesmos setores empresariais vistos anteriormente e os nós receptores são agora resultantes do agrupamento, por partido, de todos os candidatos a este cargo.

A figura 2 apresenta o grafo da rede deputado federal e exibe o fluxo de dinheiro entre setores empresariais e candidaturas agregadas por partido. Os nós estão dimensionados pelos montantes doados ou recebidos. A espessura das arestas indica o peso dos relacionamentos entre os nós, dado pelo volume transacionado entre cada par de nós. As cores dos nós representam os tipos: verdes são candidatos agregados por partidos; vermelhos, setores empresariais por seção CNAE. Aqui também aplicamos uma distribuição/leiaute, Fruchterman-Reingold. 


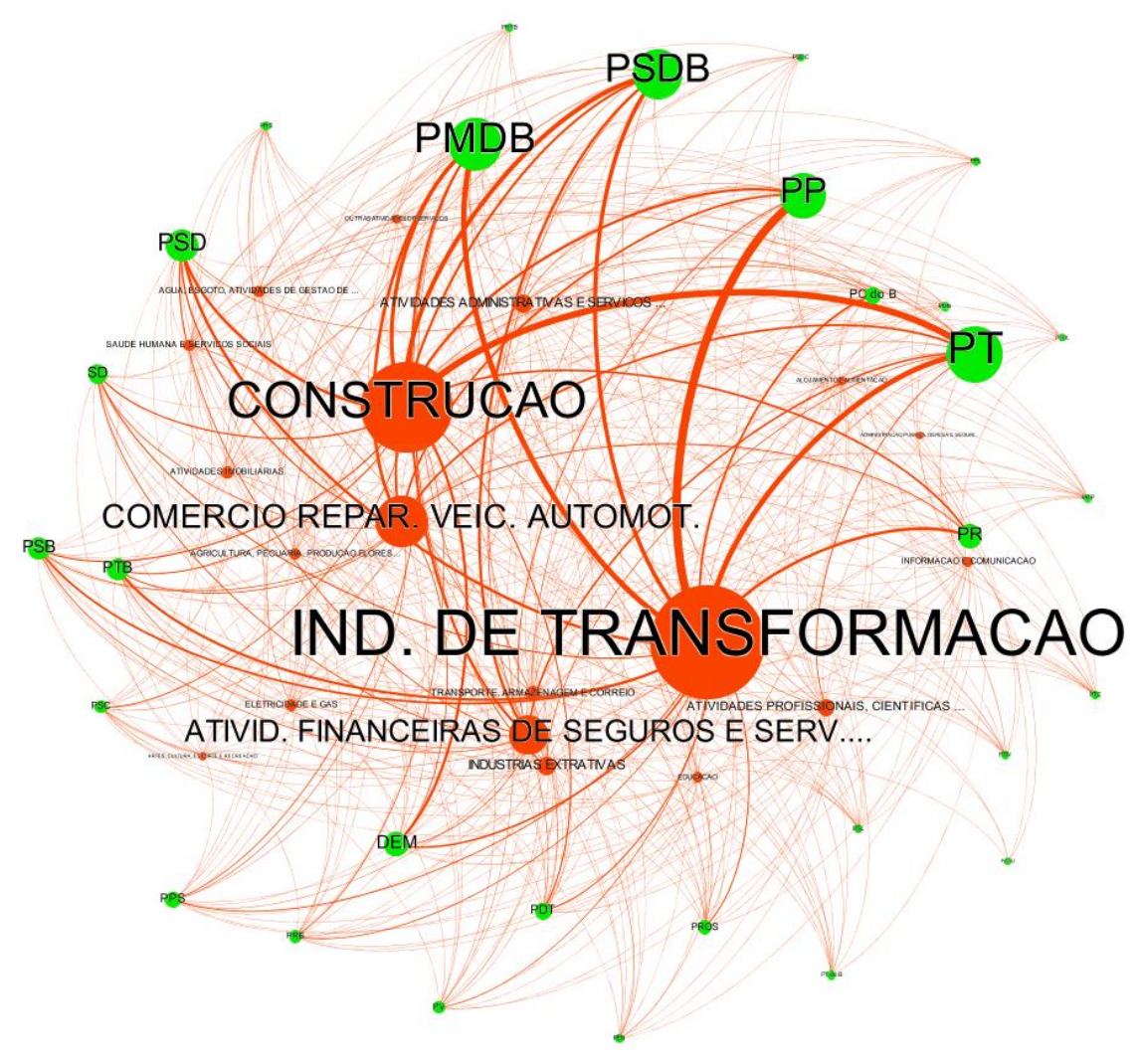

Figura 2 - Grafo Rede Deputado Federal

Fonte: elaboração própria com dados do TSE

Como se pode observar nas Tabelas 3 e 4, o PT é o único partido que apresenta grau de entrada 19, o que significa que ele recebeu de todos os setores que doaram para candidatos a deputado federal naquela eleição. À exceção de dois pequenos partidos de esquerda, PCO e PCB, que não receberam doações, e do PSTU, que recebeu de cinco setores, todas as agremiações tiveram candidatos beneficiados com doações de, no mínimo, 10 diferentes setores empresariais. Os grandes e médios partidos preponderaram nas primeiras posições, não se encontrando nenhuma agremiação desses portes na metade de baixo do ranking.

Já os setores empresariais pulverizaram suas doações. Três setores - Indústria de transformação; Informação e comunicação; e Atividades profissionais, científicas e técnicas doaram para todos os 30 partidos com candidatos que receberam algum dinheiro empresarial na campanha. Vale ressaltar que os dois últimos setores congregam empresas como agências de publicidade, assessorias jurídicas e escritórios de advocacia, por exemplo. Praticamente todos os outros setores doadores (com exceção de administração pública, defesa e seguridade social) contribuíram para a maioria ou quase a totalidade dos partidos que disputaram vagas na Câmara com recursos empresariais. Tal quadro torna, portanto, necessário explorar as demais medidas de centralidade, de modo a identificar diferenças entre agremiações e setores empresariais.

Quanto ao grau ponderado de entrada, centraremos a discussão nos, então, três principais partidos brasileiros: PT, PMDB e PSDB. Juntos, esses partidos amealharam 41\% dos 780 milhões 
de reais doados por empresas para as campanhas a deputado federal. A concentração, nesse caso, foi muito mais equilibrada que a observada na eleição presidencial: aqui, o PT obteve 14,7\% das receitas, seguido pelo PMDB, com 13,6\% e pelo PSDB, com 12,7\%.

No que se refere ao grau ponderado de saída, observa-se que quatro seções da CNAE foram responsáveis por $80,4 \%$ de todas as doações empresariais, a saber: Indústria da transformação, com 32,2\% do total; Construção, 25,1\%; Comércio, reparação de veículos automotores e motocicletas, 13,4\%; e Atividades financeiras, seguros e serviços relacionados, 9,7\%. Trata-se, portanto, dos mesmos setores que predominaram na eleição presidencial, acrescidos agora do segmento comercial. Apenas este setor apresentou uma proporção de contribuições compatível com sua participação no VAB da economia brasileira em 2014: 13,6\%. Nos outros três casos, a participação no VAB foi sistematicamente inferior à proporção de doações. Entender as causas desse predomínio político setorial também nas eleições para a Câmara dos Deputados, predomínio que não corresponde ao que se observa no plano econômico, é outro desafio a ser enfrentado em pesquisas futuras.

Tabela 3 - Métricas de centralidade - Atores políticos da Rede deputado federal

\begin{tabular}{|c|c|c|c|c|c|c|}
\hline Ator & Grau entrada* & Grau saída* & Grau pond. entrada & Grau pond. saída & $\begin{array}{c}\text { Proximi } \\
\text { dade** }^{* *}\end{array}$ & $\begin{array}{c}\text { Interme } \\
\text { diação }\end{array}$ \\
\hline PT & 19 & 0 & $114.303 .464,96$ & 0,00 & 0,70 & 0,03 \\
\hline DEM & 18 & 0 & $39.611 .415,92$ & 0,00 & 0,68 & 0,01 \\
\hline PC do B & 18 & 0 & $20.840 .115,30$ & 0,00 & 0,68 & 0,01 \\
\hline PDT & 18 & 0 & 22.199.319,92 & 0,00 & 0,68 & 0,01 \\
\hline PMDB & 18 & 0 & $106.405 .172,00$ & 0,00 & 0,68 & 0,01 \\
\hline PRB & 18 & 0 & $12.096 .709,90$ & 0,00 & 0,68 & 0,01 \\
\hline PSB & 18 & 0 & $34.595 .828,18$ & 0,00 & 0,68 & 0,01 \\
\hline PSD & 18 & 0 & $57.372 .881,27$ & 0,00 & 0,68 & 0,01 \\
\hline PSDB & 18 & 0 & $99.009 .275,85$ & 0,00 & 0,68 & 0,01 \\
\hline РTB & 18 & 0 & $32.735 .232,11$ & 0,00 & 0,68 & 0,01 \\
\hline SD & 18 & 0 & $27.772 .251,87$ & 0,00 & 0,68 & 0,01 \\
\hline PP & 17 & 0 & $90.011 .850,93$ & 0,00 & 0,67 & 0,008 \\
\hline PPS & 17 & 0 & $19.880 .641,63$ & 0,00 & 0,67 & 0,008 \\
\hline PSC & 17 & 0 & $12.539 .137,99$ & 0,00 & 0,67 & 0,008 \\
\hline PV & 17 & 0 & $10.710 .573,65$ & 0,00 & 0,67 & 0,008 \\
\hline PR & 16 & 0 & $38.668 .169,91$ & 0,00 & 0,66 & 0,006 \\
\hline PROS & 16 & 0 & $15.042 .712,07$ & 0,00 & 0,66 & 0,007 \\
\hline PSL & 16 & 0 & $2.635 .000,31$ & 0,00 & 0,66 & 0,02 \\
\hline PEN & 15 & 0 & $3.440 .569,41$ & 0,00 & 0,64 & 0,005 \\
\hline
\end{tabular}




$\begin{array}{lrrrrrr}\text { PHS } & 15 & 0 & 3.097 .216,27 & 0,00 & 0,64 & 0,006 \\ \text { PMN } & 15 & 0 & 3.318 .594,73 & 0,00 & 0,64 & 0,006 \\ \text { PRP } & 15 & 0 & 1.833 .400,70 & 0,00 & 0,64 & 0,006 \\ \text { PTC } & 14 & 0 & 2.148 .420,41 & 0,00 & 0,63 & 0,005 \\ \text { PTN } & 14 & 0 & 1.860 .454,75 & 0,00 & 0,63 & 0,005 \\ \text { PPL } & 13 & 0 & 1.974 .857,27 & 0,00 & 0,61 & 0,005 \\ \text { PT do B } & 13 & 0 & 3.493 .568,35 & 0,00 & 0,61 & 0,004 \\ \text { PSDC } & 12 & 0 & 1.045 .647,61 & 0,00 & 0,60 & 0,003 \\ \text { PSOL } & 11 & 0 & 88.482,08 & 0,00 & 0,59 & 0,003 \\ \text { PRTB } & 10 & 0 & 1.304 .907,48 & 0,00 & 0,57 & 0,002 \\ \text { PSTU } & 5 & 0 & 2.420,00 & 0,00 & 0,50 & 0,000\end{array}$

* Como nesta rede o fluxo é unidirecional (ou seja, um ator só doa ou só recebe), optamos por apresentar apenas as medidas de grau de entrada e de saída que, neste caso, correspondem ao grau de cada nó.

** Centralidade de intermediação harmonizada.

Fonte: elaboração própria com dados do TSE.

Tabela 4 - Métricas de centralidade - Atores corporativos da Rede deputado federal

\begin{tabular}{|c|c|c|c|c|c|c|}
\hline Ator & $\begin{array}{c}\text { Grau } \\
\text { entrada* }\end{array}$ & $\begin{array}{l}\text { Grau } \\
\text { saída* }\end{array}$ & $\begin{array}{l}\text { Grau pond. } \\
\text { entrada }\end{array}$ & Grau pond. saída & $\begin{array}{c}\text { Proximi } \\
\text { dade }^{* *}\end{array}$ & $\begin{array}{c}\text { Interme } \\
\text { diação }\end{array}$ \\
\hline Indústrias de Transformação & 0 & 30 & 0,00 & $251.005 .680,45$ & 0,81 & 0,04 \\
\hline Informação e Comunicação & 0 & 30 & 0,00 & $6.686 .382,31$ & 0,81 & 0,04 \\
\hline $\begin{array}{l}\text { Atividades Profissionais, Científicas e } \\
\text { Técnicas }\end{array}$ & 0 & 30 & 0,00 & $20.850 .315,51$ & 0,81 & 0,04 \\
\hline Construção & 0 & 29 & 0,00 & $195.766 .093,67$ & 0,80 & 0,03 \\
\hline $\begin{array}{l}\text { Comércio; Reparação de Veículos } \\
\text { Automotores e Motocicletas }\end{array}$ & 0 & 29 & 0,00 & $104.153 .482,16$ & 0,80 & 0,03 \\
\hline Alojamento e Alimentação & 0 & 29 & 0,00 & $3.741 .118,37$ & 0,80 & 0,04 \\
\hline $\begin{array}{l}\text { Atividades Administrativas e Serviços } \\
\text { Complementares }\end{array}$ & 0 & 29 & 0,00 & $24.663 .653,34$ & 0,80 & 0,03 \\
\hline $\begin{array}{l}\text { Atividades Financeiras, de Seguros e } \\
\text { Serviços Relacionados }\end{array}$ & 0 & 28 & 0,00 & $75.375 .263,98$ & 0,78 & 0,03 \\
\hline Transporte, Armazenagem e Correio & 0 & 27 & 0,00 & $15.264 .503,16$ & 0,77 & 0,03 \\
\hline Indústrias Extrativas & 0 & 26 & 0,00 & 24.935.359,76 & 0,76 & 0,02 \\
\hline $\begin{array}{l}\text { Agricultura, Pecuária, Produção } \\
\text { Florestal, Pesca e Aquicultura }\end{array}$ & 0 & 25 & 0,00 & $8.939 .646,35$ & 0,74 & 0,02 \\
\hline Educação & 0 & 25 & 0,00 & $6.507 .965,76$ & 0,74 & 0,037 \\
\hline Eletricidade e Gás & 0 & 24 & 0,00 & $8.298 .629,85$ & 0,73 & 0,02 \\
\hline Atividades Imobiliárias & 0 & 24 & 0,00 & $11.495 .958,63$ & 0,73 & 0,02 \\
\hline Saúde Humana e Serviços Sociais & 0 & 23 & 0,00 & $8.448 .067,30$ & 0,73 & 0,02 \\
\hline $\begin{array}{l}\text { Água, Esgoto, Atividades de Gestão de } \\
\text { Residuos e Descontaminação }\end{array}$ & 0 & 19 & 0,00 & $9.732 .359,34$ & 0,66 & 0,01 \\
\hline Artes, Cultura, Esporte e Recreação & 0 & 19 & 0,00 & $679.778,72$ & 0,66 & 0,01 \\
\hline Outras Atividades de Serviços & 0 & 19 & 0,00 & $3.484 .094,17$ & 0,66 & 0,01 \\
\hline $\begin{array}{l}\text { Adm Pública, Defesa e Seguridade } \\
\text { Social }\end{array}$ & 0 & 2 & 0,00 & $9.940,00$ & 0,42 & 0,000 \\
\hline
\end{tabular}

Fonte: elaboração própria com dados do TSE. 
Nas demais métricas da rede em análise também aparecem algumas diferenças em relação à rede presidente. Enquanto nesta os candidatos e os setores alternavam-se nas primeiras posições no ranking de centralidade de proximidade, na rede deputado federal, os setores econômicos ocupam as 15 primeiras posições - só então aparece o primeiro partido, o PT, na época à frente do executivo federal. Isso provavelmente se deve às características próprias de cada uma dessas disputas. Há menor fragmentação de candidaturas competitivas em uma eleição majoritária de dois turnos, como a presidencial. Nesse contexto, as candidaturas ganham centralidade frente aos setores empresariais. Já nas eleições proporcionais, há maior pulverização do dinheiro entre as agremiações, o que reflete a grande fragmentação do sistema partidário brasileiro e, ao mesmo tempo, alimenta esta mesma fragmentação na Câmara dos Deputados, que em 2014 alcançou o maior número efetivo de partidos da história até então $(13,2)$. Complementarmente, também é possível aventar a hipótese de que as empresas de diversos setores preferem influenciar a agenda pública no legislativo, onde os custos podem ser menores e o investimento mais eficiente em um prazo mais curto. Indícios dessa dinâmica podem ser encontrados em Geara et al. (2018), trabalho que explora as relações entre as redes de financiamento de campanhas de deputados federais e a composição das comissões permanentes da Câmara dos Deputados. Outro dado a destacar é que, a despeito de ser a terceira seção CNAE que mais aporta recursos de campanha, o setor financeiro tem apenas a nona colocação na centralidade de proximidade. Isso sugere que este setor específico, formado por um número menor de grandes empresas, aposta quase todas as suas fichas em candidatos de partidos maiores e mais competitivos, e o faz mais intensamente do que outros setores.

\section{Regressão linear múltipla}

Por fim, cabe perguntar: quais características dos partidos estão associadas ao montante de financiamento eleitoral por eles recebido das seções CNAE que mais doaram na eleição para deputado federal em 2014? Para responder essa pergunta, elaboramos modelos de regressão linear múltipla com variáveis independentes do tipo dummy, apresentados a seguir. A análise dos resultados é baseada em Gujarati (2004).

Três variáveis explicativas foram incluídas em nossos modelos. A primeira é o porte do partido político, aferido conforme o tamanho de suas bancadas na Câmara dos Deputados no dia do primeiro turno da eleição de 2014. Testaremos a hipótese (H1) de que há associação positiva e significativa entre o porte da agremiação política e o volume de financiamento eleitoral a ela oferecido pelas seções CNAE sob análise. A ideia subjacente é que as empresas doadoras são atores racionais que buscam maximizar a eficiência de seus investimentos políticos. O sucesso pretérito de um partido é tomado por elas como bom indicador da expectativa de sucesso futuro. Em outras palavras, o investimento em partidos de maior porte minimizaria a perspectiva de desperdício de seus recursos políticos (MANCUSO, HOROCHOVSKI e CAMARGO, 2018). Por 
meio de análise de clusters, os partidos políticos que apresentaram candidatos à Câmara dos Deputados na eleição de 2014 foram divididos em três grupos: grandes, médios e pequenos. Os partidos políticos de porte pequeno foram tomados como grupo de referência em nossos modelos ${ }^{9}$.

A segunda variável é a ideologia do partido político, aferida a partir de surveys realizados por Cesar Zucco Jr. junto a congressistas brasileiros ${ }^{10}$. A hipótese testada aqui (H2) é que partidos de esquerda recebem significativamente menos recursos das seções CNAE vis-à-vis os partidos de centro e de direita. Esta hipótese se justifica porque partidos autoidentificados à esquerda tendem a ser mais críticos aos interesses da classe empresarial que os partidos de outras tendências ideológicas. Em função dessa postura crítica dos partidos de esquerda aos seus interesses, os empresários das diversas seções CNAE prefeririam financiar partidos de outras correntes de pensamento, situados mais ao centro e à direita do espectro ideológico. A ideia de que a ideologia partidária pode afetar o comportamento dos doadores de campanhas tem sido explorada fartamente na literatura nacional e internacional sobre financiamento político (SAMUELS, 2001a; LEMOS, MARCELINO e PEDERIVA, 2010; MCMENAMIN 2008; 2012; MANCUSO et al. 2016).

Por fim, a terceira variável é o pertencimento à base de apoio ao governo Dilma Rousseff no Congresso Nacional, no dia do primeiro turno da eleição de 2014. Esta variável foi aferida com base no Banco de Dados Legislativos do Centro Brasileiro de Análise e Planejamento (CEBRAP). Este banco de dados considera que um partido pertence à base do governo caso ele possua algum posto no gabinete ministerial ${ }^{11}$. A hipótese testada (H3) é que os partidos pertencentes à base do governo recebem significativamente mais recursos das seções CNAE, quando comparados aos partidos que não pertencem à base. A suposição que fundamenta esta hipótese é que os financiadores teriam razões para investir proporcionalmente mais em partidos da base, seja para recompensá-los por decisões benéficas tomadas ao longo do mandato presidencial, seja por acreditarem que tais partidos teriam maior expectativa de vitória (sobretudo quando o governo está bem avaliado). A literatura tem constantemente aferido o efeito desta variável sobre o financiamento político (SAMUELS 2001a; LEMOS, MARCELINO, e PEDERIVA 2010; MANCUSO et al. 2016).

Todos os resultados obtidos estão apresentados na tabela 5.

\footnotetext{
9 O método de aglomeração utilizado foi o de clusters de $\mathrm{K}$ médias, com K=3. PMDB e PT são os partidos grandes. Os partidos médios são DEM, PP, PR, PSD e PSDB. Todos os outros partidos são pequenos: PC do B, PCB, PCO, PDT, PEN, PHS, PMN, PPL, PPS, PRB, PROS, PRP, PRTB, PSB, PSC, PSDC, PSL, PSOL, PSTU, PT do B, PTB, PTC, PTN, PV e SD.

${ }^{10}$ Com base na pontuação atribuída aos partidos políticos, novamente utilizamos análise de conglomerados para identificar os partidos de esquerda, de centro e de direita. A classificação foi possível para 20 partidos. A pontuação incluída em nosso cálculo foi sempre aquela disponível para o ano mais próximo a 2014. Mais uma vez, o método de aglomeração aplicado foi o de clusters de $\mathrm{K}$ médias, com $\mathrm{K}=3$. Os partidos classificados como de esquerda foram PC do B, PSB, PSOL, PT e PSTU. As agremiações classificadas como de centro foram PDT, PPS, PROS, PV e SD. Os partidos classificados como de direita foram DEM, PMDB, PP, PR, PRB, PSC, PSD, PSDB, PTB e PTN.

${ }^{11}$ Sete partidos pertenciam à base do governo naquele momento: PC do B, PDT, PMDB, PP, PR, PRB e PT.
} 
Tabela 5 - Regressão linear múltipla

\begin{tabular}{|c|c|c|c|c|}
\hline \multirow{2}{*}{$\begin{array}{c}\text { Variáveis } \\
\text { independentes }\end{array}$} & \multicolumn{4}{|c|}{ Variável dependente (em $\mathbf{R} \$$ ) } \\
\hline & Indústria & Construção & Comércio & Finanças \\
\hline Centro & $\begin{array}{r}403.495,25 \\
(5.326 .264,56)\end{array}$ & $\begin{array}{r}259.594,29 \\
(2.932 .830,11)\end{array}$ & $\begin{array}{r}1.821 .124,75 \\
(1.686 .234,71)\end{array}$ & $\begin{array}{r}1.203 .697,63 \\
(1.845 .073,74)\end{array}$ \\
\hline Direita & $\begin{array}{r}-222.993,10 \\
(5.162 .898,87)\end{array}$ & $\begin{array}{r}-2.108 .737,28 \\
(2.842 .875,17)\end{array}$ & $\begin{array}{r}1.490 .861,50 \\
(1.634 .514,99)\end{array}$ & $\begin{array}{r}547.040,72 \\
(1.788 .482,15)\end{array}$ \\
\hline Grande & $\begin{array}{r}19.022 .885,65^{*} \\
(7.235 .956,50)\end{array}$ & $\begin{array}{r}26.647 .182,39 * * * * \\
(3.984 .374,20) \\
\end{array}$ & $\begin{array}{r}13.005 .800,54 * * * * \\
(2.290 .821,43) \\
\end{array}$ & $\begin{array}{r}11.749 .122,00 * * * \\
(2.506 .610,99) \\
\end{array}$ \\
\hline Médio & $\begin{array}{r}15.813 .705,15^{*} \\
(5.361 .892,15) \\
\end{array}$ & $\begin{array}{r}14.131 .468,86^{* * * *} \\
(2.952 .447,92) \\
\end{array}$ & $\begin{array}{r}6.168 .183,16^{* *} \\
(1.697 .514,00) \\
\end{array}$ & $\begin{array}{c}4.766 .504,01^{*} \\
(1.857 .415,50) \\
\end{array}$ \\
\hline Base & $\begin{array}{r}7.033 .716,43 \\
(4.363 .445,94)\end{array}$ & $\begin{array}{r}-1.151 .269,09 \\
(2.402 .668,05) \\
\end{array}$ & $\begin{array}{r}-292.584,53 \\
(1.381 .417,30)\end{array}$ & $\begin{array}{r}-2.145 .832,05 \\
(1.511 .543,30)\end{array}$ \\
\hline Constante & $\begin{array}{r}3.879 .343,85 \\
(4.022 .898,39) \\
\end{array}$ & $\begin{array}{r}4.672 .270,05 \\
(2.215 .150,49) \\
\end{array}$ & $\begin{array}{r}1.042 .960,10 \\
(1.273 .603,82) \\
\end{array}$ & $\begin{array}{r}1.495 .511,73 \\
(1.393 .574,06) \\
\end{array}$ \\
\hline
\end{tabular}

Fonte: Dados do TSE organizados pelos autores.

Erro padrão entre parênteses.

$$
\begin{array}{ll}
* 0,01>\mathrm{p} \leq 0,05 ; * * 0,001>\mathrm{p} \leq 0,01 ; * * * \mathrm{p} \leq 0,001 \\
\text { Indústria: } & \mathrm{N}=20 ; \mathrm{R}^{2}=0,667 ; \mathrm{R}^{2} \text { ajustado }=0,548 \\
\text { Construção: } & \mathrm{N}=20 ; \mathrm{R}^{2}=0,835 ; \mathrm{R}^{2} \text { ajustado }=0,776 \\
\text { Comércio: } & \mathrm{N}=20 ; \mathrm{R}^{2}=0,794 ; \mathrm{R}^{2} \text { ajustado }=0,721 \\
\text { Finanças: } & \mathrm{N}=20 ; \mathrm{R}^{2}=0,662 ; \mathrm{R}^{2} \text { ajustado }=0,541
\end{array}
$$

Os quatro modelos apontam que o porte da agremiação partidária é uma variável fortemente associada com o volume de recursos concedidos pelas seções CNAE que mais doaram. Comparados aos partidos pequenos, os partidos grandes receberam, em média, cerca de 19 milhões de reais a mais da indústria de transformação, 26,6 milhões a mais do setor de construção, 13 milhões a mais do segmento comercial e 11,7 milhões a mais do ramo financeiro. No caso dos partidos médios, a diferença média é menor, mas ainda assim estatisticamente significativa.

A ideologia partidária não se mostrou associada ao financiamento eleitoral setorial em nenhum caso. Em dois setores, a diferença observada acompanhou o sentido predito pela hipótese: em média, tanto os partidos de centro quanto os partidos de direita foram mais financiados pelo comércio e pelas finanças que os partidos de esquerda. Já em outros dois setores - indústria da transformação e construção -, os partidos de centro foram mais contemplados com recursos eleitorais que os partidos de esquerda, mas o contrário se observou com os partidos de direita. Os principais segmentos empresariais financiadores de campanhas parecem ser mais pragmáticos que ideológicos - financiam os partidos cuja viabilidade eleitoral é mais provada, sem dar muito peso à linha ideológica que eles professam.

Por fim, o pertencimento à base também não esteve associado ao recebimento de mais financiamento eleitoral setorial. Além disso, em três casos - construção, comércio e finanças -, o 
sinal da variável contradisse a hipótese do artigo: em média, os partidos da base receberam menos desses setores que os partidos que não detinham pastas ministeriais. A maior diferença, embora não estatisticamente significativa, ficou por conta do setor financeiro, que, em média, forneceu cerca de 2,1 milhões de reais a mais para os partidos que não compunham o governo. Aqui, a exceção ficou por conta da indústria de transformação, único setor empresarial que financiou mais os partidos governistas. Uma proposta de explicação para este fato é que, segundo diversos autores (BASTOS, 2017; BOITO, 2018; CARVALHO, 2018; SINGER, 2018), as políticas do primeiro governo de Dilma Rousseff buscaram satisfazer a agenda do setor industrial (a propalada "agenda da FIESP"), por meio, por exemplo, de juros mais baixos, crédito subsidiado via BNDES, benefícios fiscais, contenção do custo da energia elétrica, etc. $\mathrm{O}$ financiamento industrial mais abundante para os partidos governistas em 2014 - oferecido, sobretudo, por empresas do setor como a JBS - pode ser interpretado, então, como uma forma de retribuição pelo programa econômico adotado entre 2011 e 2014. Esta tentativa de explicação precisa, naturalmente, ser aprofundada em trabalhos futuros.

\section{Considerações finais}

Olhando o financiamento eleitoral setorial pelo lado da oferta, este trabalho mostrou que: 1. A grande maioria dos setores financiou as eleições à Presidência da República e à Câmara dos Deputados em 2014. Das 21 seções da CNAE, 18 (85,7\%) fizeram doações para candidatos a presidente e $19(90,5 \%)$ para candidatos a deputado federal.

2. Nenhum setor doador, em nenhuma das eleições estudadas, concentrou suas contribuições em apenas uma candidatura ou partido. Por exemplo, na eleição para a chefia do poder executivo nacional, o setor da construção dividiu seu financiamento entre seis dos 11 candidatos (54,5\% do total). Na eleição para a Câmara, quase todos os setores doaram para a maioria dos partidos, e três setores doaram para todas as agremiações (Indústria de Transformação, Informação e Comunicação, e Atividades Profissionais Científicas e Técnicas).

3. Porém, os setores empresariais responsáveis pela maior parte das doações foram poucos e praticamente os mesmos. Além disso, em geral, a participação relativa desses setores no esforço doador do empresariado superou sua participação no VAB da economia brasileira em 2014. No caso da eleição presidencial, as seções predominantes foram a indústria da transformação $(41,6 \%$ do total de doações e $12 \%$ do VAB), a indústria da construção $(26,2 \%$ das doações e $6,2 \%$ do $\mathrm{VAB}$ ) e o segmento financeiro (14,4\% das doações e $6,4 \%$ do VAB). No caso da eleição parlamentar, as seções predominantes foram quase as mesmas (indústria da transformação, 32,2\%; construção, 25,1\%; e finanças, 9,7\%), acrescidas do comércio (13,4\% das doações e 13,6\% do VAB). As razões para o predomínio desses setores podem estar no nível das firmas (por exemplo: contratos com a União) ou no nível setorial (por exemplo: grau de intervenção e de influência do executivo federal sobre o setor econômico, ou então a estrutura do 
setor em termos do número de empresas, bem como de seu porte e da parcela da atividade econômica por elas concentrada). Compreender melhor tais razões é um desafio importante para nossa agenda de pesquisa futura.

Olhando o fenômeno pelo lado da demanda, concluiu-se que:

1. A recepção de recursos empresariais foi bem disseminada, pois oito de 11 candidaturas presidenciais receberam dinheiro de empresas em 2014 (72,7\% do total), ao passo que 30 dos 32 partidos que competiram por assentos da Câmara também receberam verbas dessa fonte $(93,8 \%)$.

2. Porém, a distribuição dos recursos entre candidaturas e partidos foi bastante desequilibrada. No que se refere à eleição presidencial, as candidaturas principais foram aquelas que receberam doações de mais setores empresariais - dos 21 setores, 18 doaram para Dilma Rousseff (85,7\% do total) e 15 doaram para Aécio Neves e Eduardo Campos/Marina Silva (71,4\% do total). As outras candidaturas, pouco competitivas, receberam apenas de quatro setores, ou ainda menos. Quanto ao volume de doações recebidas, as candidaturas principais amealharam nada menos que $99,8 \%$ do total doado. Mesmo entre elas, no entanto, a distribuição foi desequilibrada, com Dilma recebendo pouco mais da metade desses valores, Aécio pouco mais de um terço e Eduardo Campos/Marina Silva cerca de um décimo do total.

Quanto à eleição para a Câmara, também se notou certo desequilíbrio entre os partidos contemplados. Os principais partidos brasileiros à época eram PT, PMDB e PSDB. O PT recebeu doações de todos os 19 setores que financiaram aquela eleição, abarcando 14,7\% do total das doações. PMDB e PSDB receberam doações de 18 setores, e amealharam, respectivamente, $13,6 \%$ e $12,7 \%$ do total. De cada 100 reais doados por empresas para a eleição a deputado federal, esses três partidos ficaram com 41 reais, e os 59 reais restantes foram divididos entre as outras 27 agremiações que também receberam algum financiamento eleitoral.

A análise de estatísticas das redes sociais do financiamento político em 2014 (centralidade de proximidade e centralidade de intermediação) indicou que:

1. Na eleição presidencial, as três principais candidaturas e os três principais setores doadores destacaram-se no centro da rede, formando assim um tipo de elite político-econômica altamente interconectada.

2. Na eleição parlamentar, a centralidade pertenceu aos principais setores doadores, em função da maior dispersão de seus recursos entre os partidos, vis-à-vis o que se observou na disputa presidencial. Em posição de destaque na parte superior da rede encontram-se os três principais partidos acima mencionados: PT, PMDB e PSDB.

Por fim, a regressão linear múltipla debruçou-se sobre fatores que poderiam explicar o nível de financiamento destinado pelos quatro principais setores empresariais doadores aos partidos políticos brasileiros, na eleição para deputado federal. Esta parte do trabalho concluiu que o fator com maior potencial explicativo para o fenômeno observado é o porte da agremiação partidária. De fato, em comparação com os partidos pequenos, os partidos médios e, sobretudo, 
grandes, recebem significativamente mais recursos eleitorais dos setores focalizados. Ideologia e pertença à base não se mostraram como fatores com efeitos estatisticamente significativos.

A principal conclusão deste trabalho é que foi pragmático o comportamento dos setores empresariais que financiaram campanhas para a presidência e para a Câmara dos Deputados no Brasil, em 2014. De fato, nenhum setor importante pareceu prender-se a ditames ideológicos ao doar para candidaturas ou partidos. No entanto, a natureza específica do pragmatismo setorial foi afetada pelas regras eleitorais da disputa para cada cargo. No caso da eleição presidencial, que é uma eleição majoritária em dois turnos, pragmatismo significou "repartir os recursos entre os candidatos que estão na frente", e se expressou por meio da divisão de doações entre as principais candidaturas adversárias, sobretudo aquelas que lograram disputar a segunda rodada eleitoral, independentemente do perfil ideológico, mesmo que a divisão das contribuições entre elas não tenha sido exatamente igualitária. Já no caso da eleição para deputado federal, que é uma eleição proporcional, pragmatismo significou "repartir os recursos entre os partidos maiores", ainda que as agremiações de maior porte possuam perfis ideológicos distintos, ou ainda que algumas delas pertençam à base do governo, enquanto as outras pertencem à oposição.

\section{Referências}

ARAÚJO, Victor; SILOTTO, Graziele C.; CUNHA, Lucas R. Capital político e financiamento eleitoral no Brasil: uma análise empírica da estratégia das empresas na alocação de recursos de campanha. Teoria \& Sociedade. Belo Horizonte, v. 23, n. 2, p. 126-58, 2015.

ARAÚJO, Gustavo B. O déficit entre acordado e realizado no Mercosul: a influência dos grupos de interesse e o estudo do caso brasileiro. Tese de Doutorado. Universidade de São Paulo, 2008.

ARAÚJO, Gustavo B . Contribuições de campanha influenciam decisões públicas? O caso dos contratos públicos federais e das emendas ao orçamento no Brasil. Tese de Doutorado. Universidade de São Paulo, 2012.

BANDEIRA-DE-MELLO, Rodrigo; MARCON, Rosilene. Unpacking firm effects: modeling political alliances in variance decomposition of firm performance in turbulent environments. Revista de Administração Contemporânea, v. 9, n. 11, p. 65-85, 2005.

BASTOS, Pedro P. Z. Ascensão e crise do governo Dilma Rousseff e o golpe de 2016: poder estrutural, contradição e ideologia. Revista de Economia Contemporânea, v. 21, n. 2, 2017, p.23-34.

BOAS, Taylor C.; HIDALGO, F. Daniel; RICHARDSON, Neal P. The spoils of victory: campaign donations and government contracts in Brazil. The Journal of Politics, v. 76, n. 2, p. 415-429, 2014.

BOITO JÚNIOR, Armando; Reforma e crise política no Brasil: os conflitos de classe nos governos do PT. Editora Unicamp, 2018.

CARVALHO, Laura. Valsa brasileira: do boom ao caos econômico. São Paulo: Editora Todavia, 2018.

CERVI, Emerson U. Financiamento de campanhas e desempenho eleitoral no Brasil: análise das contribuições de pessoas físicas, jurídicas e partidos políticos às eleições de 2008 nas capitais de 
Estado. Revista Brasileira de Ciência Política, v. 4, n. 4, p. 135-148, 2010.

CERVI, Emerson U.; HOROCHOVSKI, Rodrigo R.; JUNCKES, Ivan J. Redes de doadores e financiamento político em 2014: distinguindo doações para candidatos, partidos e comitês financeiros nas eleições presidenciais brasileiras. E-Legis, v. 8, n. 18, p. 80-100, 2015.

CLAESSENS, Stijn; FEIJEN, Erik; LAEVEN, Luc. Political connections and preferential access to finance: The role of campaign contributions. Journal of financial economics, v. 88, n. 3, p. 554-580, 2008.

DEGENNE, Alain; FORSÉ, Michel. Introducing social networks. London: Sage, 1999.

GEARA, Geara, L.; JUNCKES, Ivan J.; HOROCHOVSKI, Rodrigo R.; CLEMENTE, Augusto J. O financiamento eleitoral nas comissões permanentes da Câmara dos Deputados: uma análise do meta relacionamento entre empresas e parlamentare. E-Legis, v. 11, n. 26 p. 60-81, 2018.

GUJARATI, Damodar N. Basic econometrics. London: Tata McGraw-Hill Education, 2009.

Higgins, Silvio S.; RIBEIRO, Antonio C. A. Análise de redes em Ciências Sociais. Brasília: Editora da Enap, 2018.

HOROCHOVSKI, Rodrigo R.; JUNCKES, Ivan J.; SILVA, Edson A.; SILVA, Joseli M.; CAMARGO, Neilor. F. Redes de partidos políticos tecidas por financiadores: um estudo das eleições de 2010 no Brasil. Revista Teoria \& Sociedade, v. 23, n. 2, p. 49-78, 2015.

HOROCHOVSKI, Rodrigo R.; JUNCKES, Ivan J.; SILVA, Edson A.; SILVA, Joseli M.; CAMARGO, Neilor F. Estruturas de poder nas redes de financiamento político nas eleições de 2010 no Brasil. Revista Opinião Pública, v. 22, n. 1, p. 28-41, 2016.

JUNCKES, Ivan J.; HOROCHOVSKI, Rodrigo R.; CAMARGO, Neilor F.; SILVA, Joseli M.; SILVA, Edson A.; ALMEIDA, Leandro B. Posicionamento das mulheres na rede de financiamento eleitoral e seu desempenho nas eleições de 2010 no Brasil: A dinâmica estrutural da exclusão e marginalização feminina no poder político. Revista Latino-Americana de Geografia e Gênero, v. 6, n. 1, p. 25-47, 2015.

JUNCKES, Ivan J.; HOROCHOVSKI, Rodrigo R.; CAMARGO, Neilor F.; SILVA, Edson A.; CHIMIN JUNIOR, Alides. B. Poder e Democracia: Uma análise da rede de financiamento eleitoral em 2014 no Brasil. Revista Brasileira de Ciências Sociais, v. 34, n. 100, p. 1-22, 2019.

LAZZARINI, Sergio G.; MUSACCHIO, Aldo; BANDEIRA DE MELLO, Rodrigo; MARCON, Rosilene. What do development banks do? Evidence from Brazil, 2002-2009. Harvard Business School, Working Paper, v. 12, n. 47, p. 12-47, 2011.

LEMIEUX, Vincent; OUIMET, Mathieu; PEREIRA, Sérgio. Análise estrutural das redes sociais. Lisboa: Instituto Piaget, 2008.

LEMOS, Leany B.; MARCELINO, D.; PEDERIVA, João H. Porque dinheiro importa: a dinâmica das contribuições eleitorais para o Congresso Nacional em 2002 e 2006. Opinião pública, v. 16, n. 2, p. 366-393, 2010.

LOPES, Alex D. Financiamento de campanhas eleitorais e empréstimos do BNDES: lobby e interesses privados. Dissertação de Mestrado em Administração. Universidade Federal de Goiás, 2016.

MANCUSO, Wagner P. Investimento eleitoral no Brasil: balanço da literatura (2001-2012) e agenda de pesquisa. Revista de Sociologia e Política, v. 23, n. 54, p. 155-183, 2015.

MANCUSO, Wagner P.; SPECK, Bruno W. Financiamento empresarial na eleição para deputado federal (2002-2010): determinantes e consequências. Teoria \& Sociedade, v. 23, n. 2, p. 103-25, 2015.

MANCUSO, Wagner P.; SPECK, Bruno W. Os preferidos das empresas: um estudo de determinantes do financiamento eleitoral empresarial. Empresários, desenvolvimento, cultura e democracia. Curitiba: Editora da UFPR, p. 185-195, 2015. 
MANCUSO, Wagner P., FIGUEIREDO FILHO, Dalson B., SPECK, Bruno W., SILVA, Lucas E. O.; ROCHA, Enivaldo C. Corporate Dependence in Brazil's 2010 Elections for Federal Deputy. Brazilian Political Science Review, v. 10, n. 3, p. 1-24, 2016.

MANCUSO, Wagner P.; HOROCHOVSKI, Rodrigo R.; CAMARGO, Neilor F. Empresários e financiamento de campanhas na eleição presidencial brasileira de 2014. Teoria \& Pesquisa, v. 25, n. 3, p. 38-64, 2016.

MANCUSO, Wagner P.; HOROCHOVSKI, Rodrigo R.; CAMARGO, Neilor F. Financiamento eleitoral empresarial direto e indireto nas eleições nacionais de 2014. Revista Brasileira de Ciência Política, n. 27, p. 9-36, 2018.

MCMENAMIN, Iain. Business, politics and money in Australia: testing economic, political and ideological explanations. Australian Journal of Political Science, v. 43, n. 3, p. 377-393, 2008.

MCMENAMIN, Iain. If money talks, what does it say? Varieties of capitalism and business financing of parties. World Politics, v. 64, n. 1, p. 1-38, 2012.

NEWMAN, Mark. Networks. Oxford: Oxford University Press, 2018.

SAMUELS, David. Money, elections, and democracy in Brazil. Latin American Politics and Society, v. 43, n. 2, p. 27-48, 2001.

SAMUELS, David. Does money matter? Credible commitments and campaign finance in new democracies: theory and evidence from Brazil. In: SAMUELS, David (Ed.) Comparative Politics, p. 23-42, 2001.

SAMUELS, David. When does every penny count? Intra-party competition and campaign finance in Brazil. Party politics, v. 7, n. 1, p. 89-102, 2001.

SAMUELS, David. Incumbents and challengers on a level playing field: assessing the impact of campaign finance in Brazil. Journal of Politics, v. 63, n. 2, p. 569-584, 2001.

SAMUELS, David. Pork barreling is not credit claiming or advertising: Campaign finance and the sources of the personal vote in Brazil. Journal of Politics, v. 64, n. 3, p. 845-863, 2002.

SANTOS, Bruno. C. Interesses econômicos, representação política e produção legislativa no Brasil sob a ótica do financiamento de campanhas eleitorais. Tese de doutorado. Universidade Federal de Minas Gerais, 2016.

SANTOS, R. D. A economia política das eleições 2002: um estudo sobre a concentração de financiamento de campanha para deputado federal. Dissertação de mestrado. Universidade Federal Fluminense, Niterói, 2009.

SCOTT, J. Social network analysis. London: Sage, 2012.

SILVA, Edson A.; JUNCKES, Ivan J.; HOROCHOVSKI, Rodrigo R.; CAMARGO, Neilor F.; SILVA, Joseli M. Mulheres nas Eleições de 2014 no Brasil: Evidências de Exclusão e Marginalização Política. Revista Latino-Americana de Geografia e Gênero, v. 8, n. 1, p. 251272, 2017.

SINGER, André. O lulismo em crise: um quebra-cabeça do período Dilma (2011-2016). São Paulo: Companhia das Letras, 2018.

SPECK, Bruno W. Influenciar as eleições ou garantir acesso aos eleitos?: O dilema das empresas que financiam campanhas eleitorais. Novos Estudos, n. 104, p. 39-59, 2016.

Artigo recebido em: 2020-04-18

Artigo reapresentado em: 2020-06-18

Artigo aceito em: 2020-06-23 